\title{
openheart Association of high-density lipoprotein cholesterol with non- fatal cardiac and non-cardiac events: a CANHEART substudy
}

\author{
Harindra C Wijeysundera, ${ }^{1,2,3}$ Maria Koh, ${ }^{3}$ David A Alter, ${ }^{3}$ Peter C Austin, ${ }^{2,3}$ \\ Cynthia A Jackevicius, ${ }^{2,4}$ Jack V Tu, ${ }^{1,2,3}$ Dennis T Ko ${ }^{1,2,3}$
}

\begin{abstract}
- Additional material is published online only. To view please visit the journal online (http://dx.doi.org/10.1136/ openhrt-2017-000731)
\end{abstract}

To cite: Wijeysundera $\mathrm{HC}$, Koh M, Alter DA, et al. Association of high-density lipoprotein cholesterol with non-fatal cardiac and noncardiac events: a CANHEART substudy. Open Heart 2017;4:e000731. doi:10.1136/ openhrt-2017-000731

Received 1 October 2017 Revised 8 November 2017 Accepted 14 November 2017

\section{(a) CrossMark}

'Division of Cardiology, Schulich Heart Centre, Sunnybrook Health Sciences Centre, University of Toronto, Toronto, Canada ${ }^{2}$ Institute of Health Policy, Management and Evaluation, University of Toronto, Toronto, Canada

${ }^{3}$ Institute for Clinical Evaluative Sciences (ICES), Toronto, Canada ${ }^{4}$ College of Pharmacy, Western University of Health Sciences, Pomona, California, USA

Correspondence to Dr Harindra C Wijeysundera; Harindra.wijeysundera@ sunnybrook.ca

\section{ABSTRACT}

Background Emerging evidence has questioned the role of high-density lipoprotein cholesterol (HDL-C) as an independent and modifiable risk factor for cardiovascular disease. We sought to understand the relationship between HDL-C levels and subsequent non-fatal clinical events. Methods Individuals without prior cardiovascular disease or cancer were identified. Outcomes of interest were classified as non-fatal cardiovascular, cancer and infectious. Sex-stratified, multivariable, cause-specific Cox proportional hazards models were created. The reference level HDL-C for both women and men was $51-60 \mathrm{mg} / \mathrm{dL}$. Results Our cohort consisted of 631762 individuals. For cardiovascular events, there was a consistent inverse relationship, with higher adjusted HRs for the lower HDL-C strata in both men and women. This relationship was also seen in the composite of non-cardiovascular outcomes. In women, the HR in the $<30 \mathrm{mg} / \mathrm{dL} H D L-C$ category was 2.10 (95\% Cl 1.66 to 2.57$)$ and 1.86 (95\% Cl 1.27 to 2.72$)$ for cardiovascular and non-cardiovascular outcomes, respectively; in contrast, in the $>90 \mathrm{mg} / \mathrm{dL}$ group, it was 0.87 (95\% Cl 0.74 to 1.02$)$ and 0.81 (95\% Cl 0.63 to 1.06$)$. For men, HRs were $2.02(95 \% \mathrm{Cl} 1.79$ to 2.28$)$ and 1.84 (95\% $\mathrm{Cl} 1.47$ to 2.31 ) in the $<30 \mathrm{mg} / \mathrm{dL}$ HDL-C category for cardiovascular and non-cardiovascular outcomes, respectively, compared with $0.73(95 \% \mathrm{Cl} 0.53$ to 1.00$)$ and $1.07(95 \% \mathrm{Cl} 0.67$ to 1.70$)$ in the $>90 \mathrm{mg} / \mathrm{dL}$ group. Conclusions We found an inverse relationship between HDL-C and a wide spectrum of non-fatal outcomes, suggesting that $\mathrm{HDL}-\mathrm{C}$ is a heavily confounded factor that may be a marker of poor overall health, rather than an independent and modifiable risk factor.

\section{INTRODUCTION}

There has been compelling high-quality and consistent epidemiological evidence suggesting a relationship between increased levels of high-density lipoprotein cholesterol (HDL-C) and a lower incidence of cardiovascular events such as myocardial infarction (MI) as well as cardiovascular mortality. ${ }^{1-11}$ This has laid the foundation for the hypothesis that HDL-C has a causative role in cardiovascular disease and that it is protective against atherosclerosis. ${ }^{12} 13$

\section{KEY QUESTIONS}

What is already known about this subject? High-density lipoprotein cholesterol (HDL-C) levels have a heavily confounded relationship with cardiovascular disease, based on cardiovascular and non-cardiovascular mortality. Relationship between HDL-C levels and non-fatal clinical events is understudied.

\section{What does this study add?}

We observed an inverse relationship between HDL-C and wide spectrum of non-fatal outcomes was seen. These findings suggest higher HDL-C levels are a marker of poor overall health.

How might this impact on clinical practice? This will reinforce the notion that HDL-C levels are not a target for intervention but rather a marker of health.

The traditional view of HDL-C as an independent and modifiable cardiovascular risk factor has been challenged by emerging evidence from human genetic studies and randomised controlled trials of pharmacological agents which increase HDL-C as a therapeutic target. ${ }^{11} 1314$ Mendelian randomised studies have found no clear association between extremely low levels of HDL-C cholesterol secondary to inherited mutations in lipoprotein metabolism and premature coronary disease. ${ }^{15-17}$ Trials of HDL-C raising drugs have, as a group, failed to show a relationship between increasing the concentrations of HDL-C cholesterol and improved cardiovascular outcomes. ${ }^{18-21}$ Moreover, HDL-C has been shown to be associated with other factors such as obesity, degree of glycaemic control, smoking, exercise and alcohol, further confounding its apparent independent relationship with cardiovascular disease. ${ }^{13}$ Previous work from our group has further reinforced this concept that HDL-C has a heavily confounded relationship with 


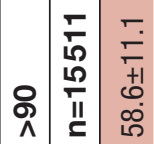

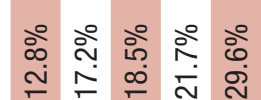

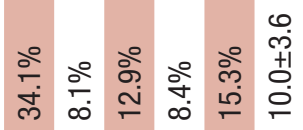

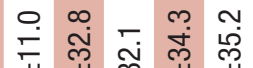

+1

क

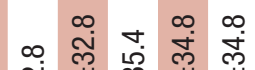

苗

峁芒

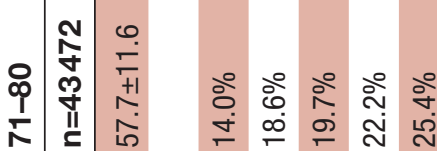

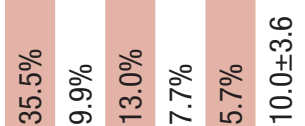

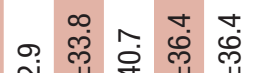

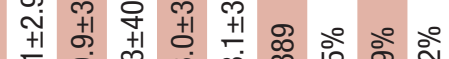

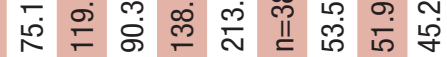

灾

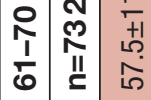

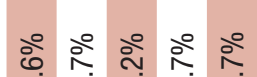

मீं क्ष

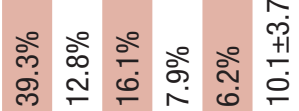

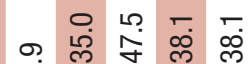

+1 +1 +1 +1 +1 ปู่

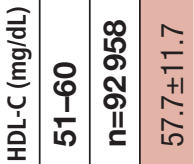

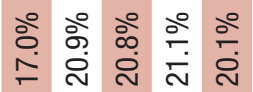

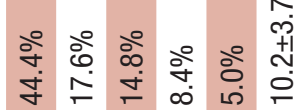

๑) मृ

ᄀ.

芰

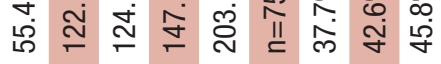

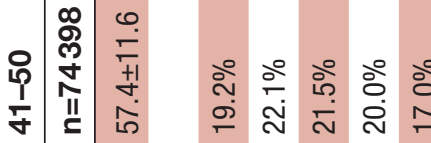

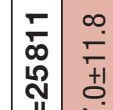

ल $\stackrel{\text { II }}{\mathrm{L}}$

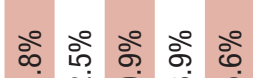

กั ลิ่

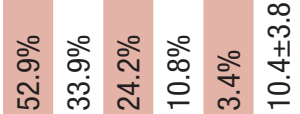

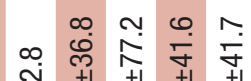

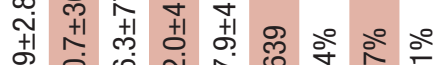

守 穴

过 㝏

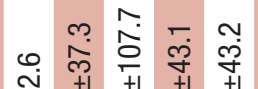

萡

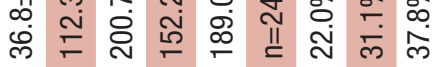

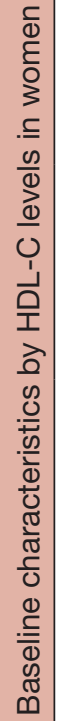

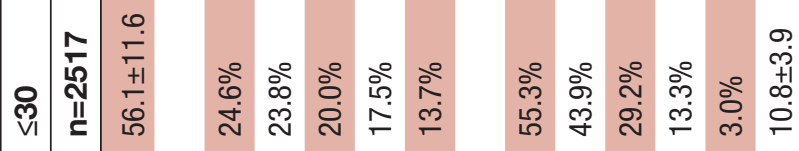

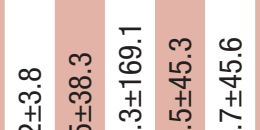

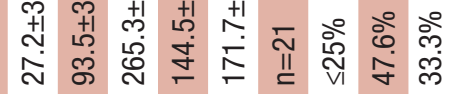

둥

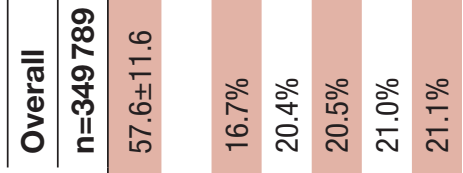

วั ํำ

市 +1

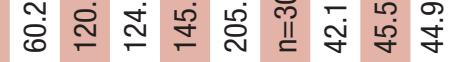

ษ 
cardiovascular disease by examining the association with HDL-C cholesterol with cardiovascular and non-cardiovascular mortality. ${ }^{22}$

In addition to the previous literature examining the relationship of HDL-C with non-fatal cardiovascular disease ${ }^{23}$ there are also data evaluating the relationship of HDL-C with incident non-cardiovascular events such as cancer ${ }^{24-32}$ or infections. ${ }^{33-38}$ However, to our knowledge, there has been no published literature evaluating the relationship of HDL-C to cardiovascular and non-cardiovascular non-fatal events in the same population. If a similar relationship of HDL-C to both cardiovascular and non-cardiovascular events was observed, this would further challenge the plausibility of HDL-C as an independent risk factor specific for cardiovascular disease and build upon our previous work which evaluated fatal outcomes. Unlike cause-specific mortality, which may be prone to misclassification, non-fatal cardiovascular versus non-cardiovascular events may be more accurate outcomes with which to understand if there is a differential association with HDL-C levels. Accordingly, to address this gap in knowledge, we made use of the Cardiovascular Health in Ambulatory Care Research Team (CANHEART) cohort, a large primary prevention 'big data' database in Ontario, Canada, to study the association between HDL-C and non-fatal cardiovascular and non-cardiovascular events.

\section{METHODS}

Our study was conducted in the province of Ontario, which is Canada's largest province with a population of approximately 13.6 million, all of whom received publicly funded universal medical coverage, provided by a single third-party payer, the Ontario Ministry of Health and Long-Term Care.

\section{Data sources}

The cohort was derived from the CANHEART cohort which was constructed by linking multiple individual-level databases using encoded personal identifiers. ${ }^{39}$ Databases that were linked include Canadian Institute for Health Information Discharge Abstract Database, Same Day Surgery and National Ambulatory Care Reporting System to identify inpatient hospitalisations and emergency room visits, respectively; Registered Persons Database for death information; and Gamma-Dynacare Medical Laboratories for laboratory results including lipid panel analysis. HDL-C information was gathered from the Gamma-Dynacare Medical Laboratories which captures $25 \%-30 \%$ of all outpatient laboratory testing in Ontario. For additional information on the 17 data sources used to create the CANHEART cohort, please see www.canheart.ca. ${ }^{39}$

Individuals who were between 40 and 105 years old on 1 January 2008 and did not have prior cardiovascular conditions and comorbidities (acute MI, coronary heart failure, stroke, percutaneous coronary intervention, coronary artery bypass grafting, cancer, dementia, peripheral vascular disease, abdominal aortic aneurysm and venous thrombus) for the previous 20 years were included in our study cohort. Individuals who were longterm nursing home residents, had invalid postal code and did not have full cholesterol panel 1 year prior to 1 January 2008 were excluded. The end of follow-up period was 31 December 2012.

\section{Exposure and outcomes}

National guidelines in Canada recommend screening lipid profiles for men over the age of 40 and women over the age of 50 , to be conducted every $1-3$ years. ${ }^{40}$ If the individual had multiple HDL-C measures, the measurement closest to 1 January 2008 was used as the exposure measurement. HDL-C was divided into eight categories starting at less than or equal to $30 \mathrm{mg} / \mathrm{dL}$, in increments of $10 \mathrm{mg} / \mathrm{dL}$, to greater than $90 \mathrm{mg} / \mathrm{dL}$.

The primary outcome of our study was non-fatal outcomes, defined using the International Classification of Diseases, 10th revision, ascertained using the administrative databases linked as part of the CANHEART cohort. Non-fatal outcomes that were included were the most common cardiovascular and non-cardiovascular events. Cardiovascular outcomes were MI or angina, stroke, cardiac arrest and the composite of the four conditions. For non-cardiovascular outcomes, we chose those that have had previous associations with HDL-C, specifically a composite of cancers, sepsis and pneumonia. We also reported each of the cancer outcomes separately, which included all cancer, breast, prostate, lung and colorectal cancer.

\section{Statistical analysis}

We stratified the analysis by sex, given that the relevant cancers for women and men are different and we hypothesised that there may be distinct relationships of HDL-C and outcomes for each sex. We computed the age-standardised morbidity rate for each HDL-C category using the 2006 Canadian population as the reference population. Cause-specific hazard models were used to estimate the effect of HDL-C cholesterol on the rate of non-fatal outcomes. ${ }^{41}{ }^{42}$ Death was treated as a competing event in these models as occurrence of death precludes from observing the non-fatal readmissions. The model was adjusted for age, quintiles of median neighbourhood income, non-HDL-C cholesterol, log of triglycerides, smoking status, and Johns Hopkins' Aggregated Diagnosis Groups (ADG) score. Smoking status was not available in all individuals, and therefore was imputed based on other baseline characteristics. Other lifestyle factors (alcohol, body mass index, diet and physical activity) were not included due to excessive missing data. The ADG score as a measure of comorbidity burden has been shown to be an accurate prognostic factor in a general ambulatory population. ${ }^{43}$ The reference level HDL-C for both women and men was $51-60 \mathrm{mg} / \mathrm{dL}$ and all analyses were stratified by sex. 


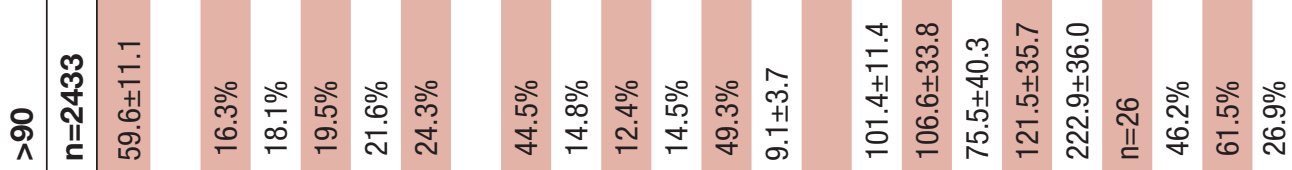

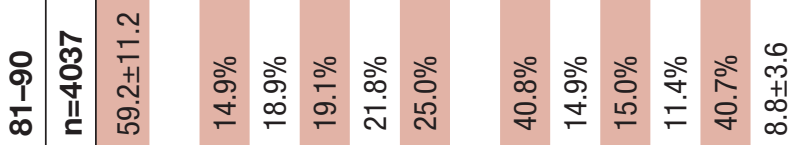

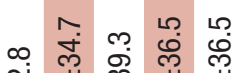

范苗

品

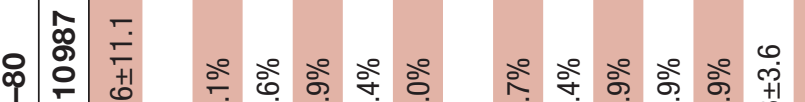

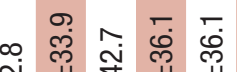

六 II

華

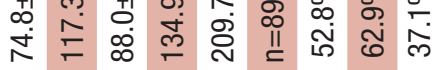

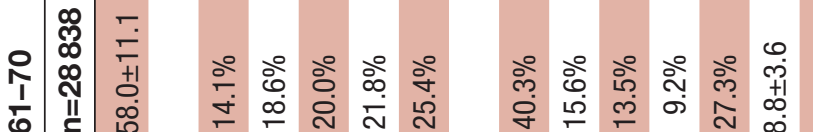

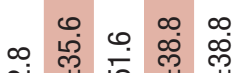

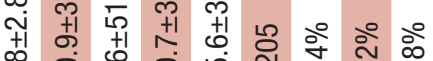

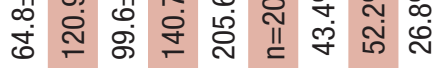

흔

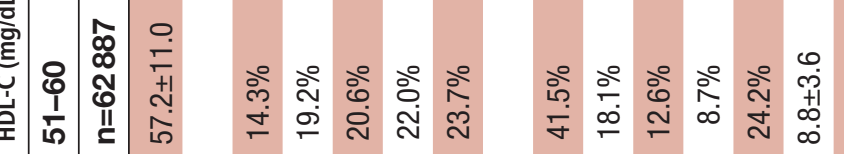

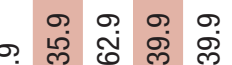

న

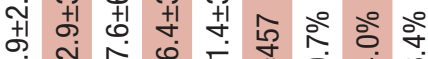

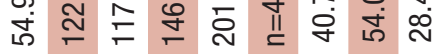

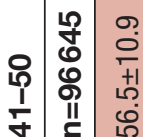

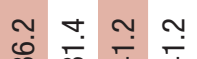

每

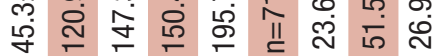

लำ

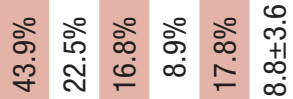

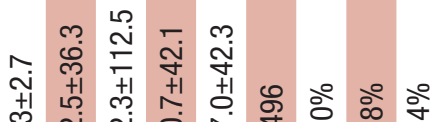

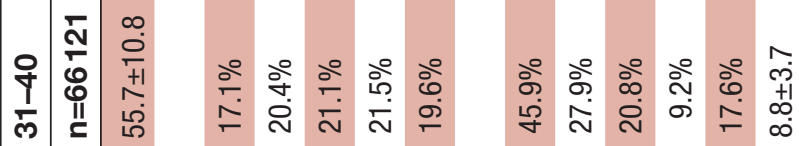

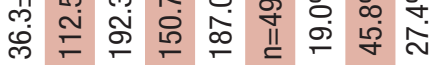

$\stackrel{c}{\mathbb{d}}$

$\stackrel{\varepsilon}{\subseteq}$

$\frac{\infty}{0}$

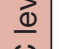

몬

즐

o

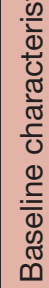

垔

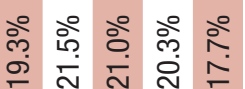

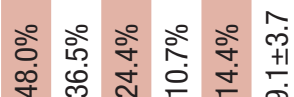

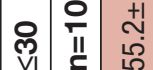

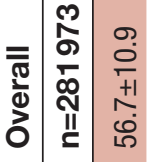

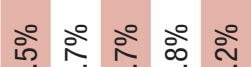

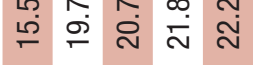

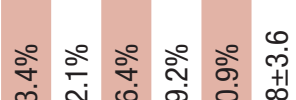

भ่ ลี
-

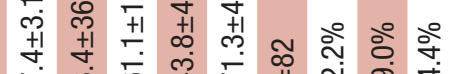

ล

일

+1

守它 守守

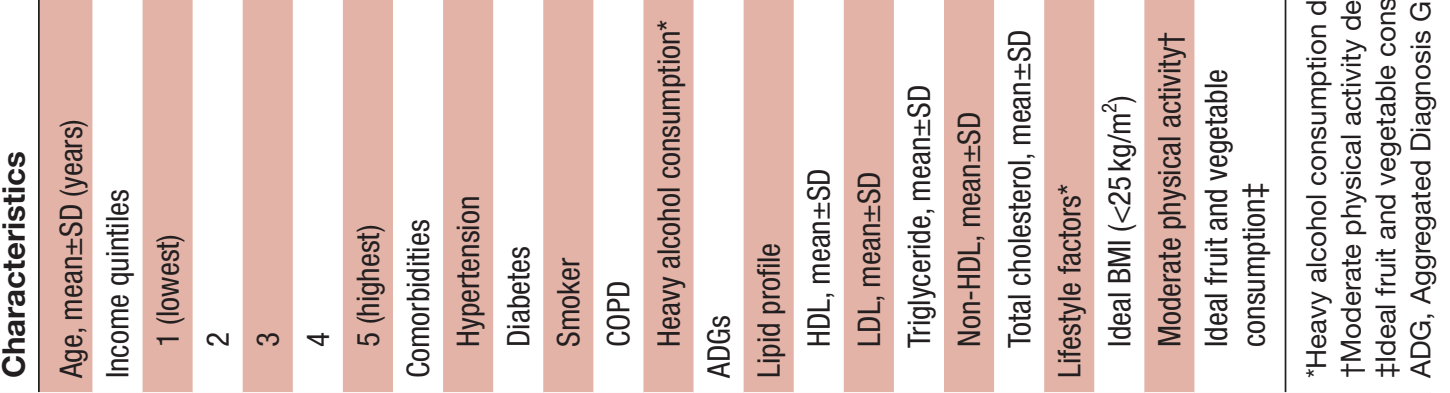

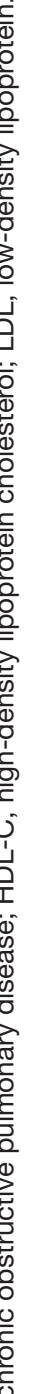

$\stackrel{2}{7}$

$\stackrel{\vec{F}}{\stackrel{9}{+}}$

등

ब

잉

$\vec{\omega}$

윰

N

$\vec{v}$

ठे

$\stackrel{0}{\bar{D}}$ 
Table 3 Age-standardised cause-specific non-fatal cardiovascular (per 1000 persons-years) by HDL-C levels*

\begin{tabular}{|c|c|c|c|c|c|c|c|c|c|}
\hline \multirow[b]{3}{*}{ Outcome } & \multicolumn{9}{|c|}{ HDL-C (mg/dL) } \\
\hline & Overall & $\leq 30$ & $31-40$ & $41-50$ & $51-60$ & $61-70$ & $71-80$ & $81-90$ & $>90$ \\
\hline & $n=349789$ & $\mathrm{n}=2517$ & $n=25811$ & $n=74398$ & $n=92958$ & $\mathrm{n}=73207$ & $n=43472$ & $\mathrm{n}=21915$ & $\mathrm{n}=15511$ \\
\hline Composite CV & 3.6 & 8.4 & 5.6 & 4.4 & 3.6 & 3.0 & 2.8 & 2.5 & 2.9 \\
\hline Ml/angina & 2.0 & 4.2 & 3.3 & 2.6 & 1.9 & 1.7 & 1.5 & 1.2 & 1.2 \\
\hline \multirow[t]{2}{*}{ Cardiac arrest } & 0.1 & 0.2 & 0.1 & 0.1 & 0.1 & 0.0 & 0.0 & 0.0 & 0.1 \\
\hline & $n=281973$ & $n=10025$ & $n=66121$ & $n=96645$ & $n=62887$ & $n=28838$ & $n=10987$ & $n=4037$ & $n=2433$ \\
\hline \multicolumn{10}{|l|}{ Men } \\
\hline Composite CV & 5.5 & 9.0 & 7.1 & 5.6 & 4.8 & 3.7 & 3.6 & 3.3 & 3.2 \\
\hline
\end{tabular}

${ }^{*}$ Age-standardised morbidity rate calculated using the 2006 Canadian population as the standard population.

CV, cardiovascular; HDL-C, high-density lipoprotein cholesterol; MI, myocardial infarction.

Analyses were performed with the use of SAS software, V.9.3 (SAS Institute).

\section{RESULTS \\ Cohort}

The details of the cohort selection are found in online supplementary appendix efigure 1 . The CANHEART cohort consisted of 6372670 residents. Of these, 5501941 represented a primary prevention cohort without prior cardiovascular disease. Within the primary prevention population, $631762(11.4 \%)$ had a cholesterol profile performed in the 1 year prior to 1 January 2008 and were included in the analysis cohort.

\section{Baseline characteristics}

Within the cohort, $55.4 \%$ were women, and the mean age was 57.2 years, with a mean HDL-C level of $55.2 \mathrm{mg}$ / $\mathrm{dL}$. The baseline characteristics for women and men, by HDL-C strata, are found in tables 1 and 2. In both sexes, mean age increased with HDL-C concentration, raising from 56.1 and 55.2 years in the $<30 \mathrm{mg} / \mathrm{dL}$ group for women and men, respectively, to 58.6 and 59.6 years in the $>90 \mathrm{mg} / \mathrm{dL}$ group. For income, there was an inverse relationship with HDL-C, which was most pronounced in women, where $24.6 \%$ of the $<30 \mathrm{mg} / \mathrm{dL}$ group was in the lowest income quintile compared with only $12.8 \%$ of the $>90 \mathrm{mg} / \mathrm{dL}$ group. There was a strong inverse relationship between the prevalence of the traditional risk factors of hypertension, diabetes and smoking and HDL-C strata, which was consistent in both sexes.

\section{Cardiovascular event rates}

In table 3, age-standardised event rates for each of the cardiovascular outcomes are shown for both women and men for each of the HDL-C cholesterol strata. For both sexes, there was a consistent inverse relationship, with higher events for the lower HDL-C strata. For the composite of cardiovascular events in women, there were 8.4 events $/ 100000$ person-years in the $<30 \mathrm{mg} / \mathrm{dL}$ category, compared with 2.9 events $/ 100000$ person-years for the $>90 \mathrm{mg} / \mathrm{dL}$ category. For men, the corresponding rates were 9.0 events $/ 100000$ person-years in the $<30 \mathrm{mg} /$ dL category, compared with 3.2 events/100 000 personyears for the $>90 \mathrm{mg} / \mathrm{dL}$ category.

In figure 1, the adjusted cause-specific HRs for each of the cardiovascular non-fatal outcomes are reported. The HR for each HDL-C stratum was compared with the reference of $51-60 \mathrm{mg} / \mathrm{dL}$ for both women and men. A consistent, inverse relationship was observed for both groups with the HR increased in the lower HDL-C categories, which then plateaued in the higher HDL-C strata.

\section{Non-cardiovascular event rates}

In table 4, in women, a similar inverse relationship was seen for the cancer and sepsis/pneumonia outcomes as was observed for the cardiovascular events. For the composite of all non-cardiovascular outcomes, the event rate was 17 events $/ 100000$ person-years in the $<30 \mathrm{mg} /$ dL category, and 7.3 events/100 000 person-years in the $>90 \mathrm{mg} / \mathrm{dL}$ category. However, in men, a more complex relationship was observed with cancer outcomes, where a 'U' shape was observed in all cancer, as well as lung and colorectal cancer with higher event rates in both the lowest and highest HDL-C categories. A similar, but less pronounced ' $U$ ' shape relationship was seen in the composite of all non-cardiovascular events, with an event rate of $15 / 100000$ person-years in the $<30 \mathrm{mg} / \mathrm{dL}$ HDL-C category and 10.8/100 000 person-years in the $>90 \mathrm{mg} /$ dL HDL-C group.

In figure 2, the adjusted HRs associated with HDL-C are shown for the non-cardiovascular events. For women, in the overall composite of non-cardiovascular events 


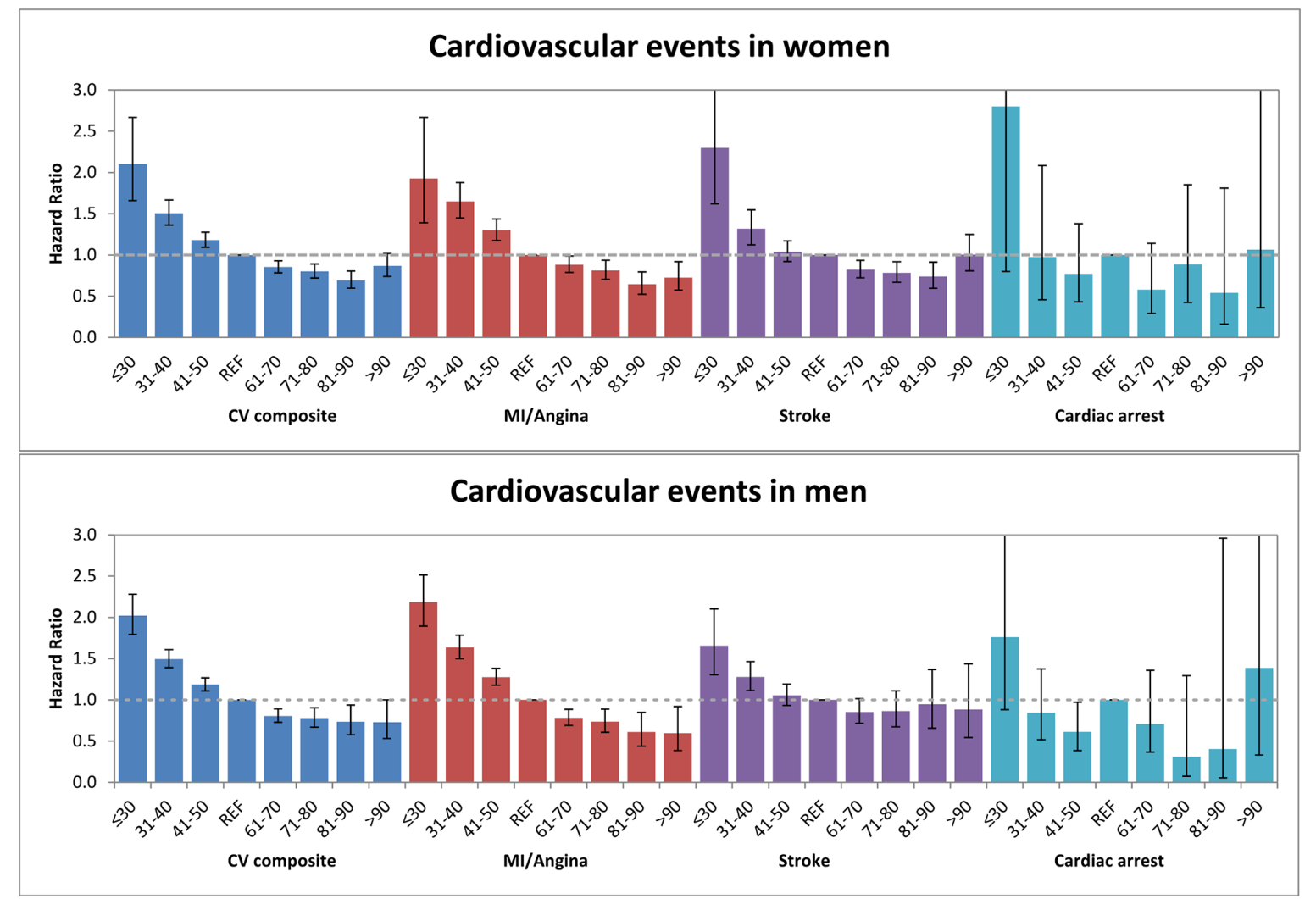

Figure 1 Non-fatal cardiovascular outcomes by high-density lipoprotein cholesterol (HDL-C) level. Adjusted cause-specific HRs for each outcome are reported, compared with reference category 51-60 mg/dL. CV, cardiovascular; MI, myocardial infarction.

(figure 2, upper panel), the $<30 \mathrm{mg} / \mathrm{dL}$ HDL-C category had an HR of 1.86 (95\% CI 1.27 to 2.72$)$, while the $>90 \mathrm{mg} / \mathrm{dL}$ HDL-C category had an HR of $0.81(95 \%$ CI 0.63 to 1.06 ) compared with the reference group. However, the overall inverse relationship was somewhat attenuated in cancer events in women, specifically for breast and lung cancer (online supplementary appendix efigure 2, panel a). As with the women, an attenuated but consistent relationship was seen in the composite of non-cardiovascular events for men, with a plateau in the higher HDL-C categories (figure 2, lower panel). Cancer in men (online supplementary appendix efigure 2, panel c) also had a relatively flat relationship.

\section{DISCUSSION}

Using a large, primary prevention cohort of over 600000 individuals, we found an inverse relationship with both cardiovascular and non-cardiovascular outcomes, reinforcing the hypothesis that HDL-C levels may be a marker of poor overall health, rather than a causative factor in either cardiovascular or noncardiovascular disease.

Lipoprotein metabolism has been a major focus of research in cardiovascular disease for decades, and indeed the causative association of low-density lipoprotein (LDL) with atherosclerosis is irrefutable, with consistent epidemiological and randomised trial data showing that lowering LDL levels are associated with a marked reduction in cardiovascular morbidity and mortality. ${ }^{35134445}$ In contrast, the relationship between HDL-C cholesterol and cardiovascular outcomes has conflicted data from epidemiological studies, which have consistently suggested a strong inverse relationship, and clinical trial data which show no association between HDL-C raising and improved outcomes.

Concurrently, there have been a number of studies evaluating the relationship between lipoprotein metabolism and other outcomes, such as cancer and sepsis. ${ }^{24-38}$ The underlying physiological rationale for a possible relationship is the role that HDL-C may play in inflammation. In sepsis and infections such as pneumonia, the studies have been generally small, and the results inconsistent and inconclusive. ${ }^{35-38}$ Although a larger literature exists studying the relationship between HDL-C and various forms of cancers, these too have been mostly small cross-sectional studies or meta-analysis with inconsistent results. The largest of these was a cohort study of 23 centres evaluating colorectal cancer in 521448 patients, which found a relatively weak inverse relationship between HDL-C levels and the incidence of proximal or distal colon cancer. $^{31}$ A meta-analysis of observational trials in breast cancer by Touvier and colleagues examined 234606 patients and found a modest but statistically significant inverse association between HDL-C levels and breast cancer, with a reduction of $14 \%$ in 
Table 4 Age-standardised cause-specific non-cardiovascular events (per 1000 persons-years) by HDL-C levels*

\begin{tabular}{|c|c|c|c|c|c|c|c|c|c|}
\hline \multirow[b]{3}{*}{ Outcome } & \multicolumn{9}{|c|}{ HDL-C (mg/dL) } \\
\hline & Overall & $\leq \mathbf{3 0}$ & $31-40$ & $41-50$ & $51-60$ & $61-70$ & $71-80$ & $81-90$ & $>90$ \\
\hline & $n=349789$ & $\mathrm{n}=2517$ & $n=25811$ & $n=74398$ & $\mathrm{n}=92958$ & $\mathrm{n}=73207$ & $n=43472$ & $\mathrm{n}=21915$ & $n=15511$ \\
\hline Non-CV & 8.5 & 17 & 11.5 & 9.6 & 8.2 & 7.8 & 7.3 & 7.1 & 7.3 \\
\hline \multicolumn{10}{|l|}{ Cancer } \\
\hline Breast & 2.6 & 3 & 2.5 & 2.7 & 2.7 & 2.6 & 2.5 & 2.7 & 2.6 \\
\hline Lung & 1.0 & 1.7 & 1.3 & 1.1 & 1.0 & 0.9 & 0.9 & 0.9 & 1.0 \\
\hline Colorectal & 1.1 & 1.6 & 1.3 & 1.3 & 1.0 & 1.0 & 1.0 & 0.9 & 1.1 \\
\hline \multicolumn{10}{|l|}{ Other } \\
\hline Sepsis/pneumonia & 2.1 & 5.1 & 3.4 & 2.6 & 2.1 & 1.8 & 1.6 & 1.6 & 1.7 \\
\hline \multicolumn{10}{|l|}{ Men } \\
\hline Non-CV & 9.6 & 15 & 11.3 & 9.3 & 8.8 & 8.4 & 8.5 & 8.8 & 10.8 \\
\hline \multicolumn{10}{|l|}{ Cancer } \\
\hline All cancer & 11.3 & 14.3 & 12.2 & 11.0 & 10.7 & 10.9 & 10.4 & 10.9 & 12.7 \\
\hline Prostate & 3.6 & 2.6 & 3.4 & 3.5 & 3.7 & 4.1 & 3.7 & 3.7 & 4 \\
\hline Lung & 1.3 & 1.9 & 1.5 & 1.2 & 1.2 & 1.1 & 1.2 & 1.8 & 1.6 \\
\hline Colorectal & 1.4 & 2.1 & 1.5 & 1.5 & 1.3 & 1.3 & 1.2 & 1.3 & 1.6 \\
\hline \multicolumn{10}{|l|}{ Other } \\
\hline
\end{tabular}

*Age-standardised mortality rate calculated using the 2006 Canadian population as the standard population.

CV, cardiovascular; HDL-C, high-density lipoprotein cholesterol.

cancer incidence per $1 \mathrm{mmol} / \mathrm{L}$ increment in HDL-C concentration. ${ }^{29}$

Our study adds to this growing literature by studying both cardiovascular and non-cardiovascular outcomes in a single, large, primary prevention population. We found a similar dose-response relationship between HDL-C and both types of outcomes. There are a number of potential explanations for our observations. The first is that both cardiovascular and non-cardiovascular outcomes share a common pathophysiological pathway on which HDL-C acts. The diverse nature of our outcomes, ranging from prostate cancer to pneumonia, makes this explanation less likely. That said, given the observational nature of our study, we cannot discount this possibility. An alternative explanation is that HDL-C is a confounded covariate, related to multiple clinical and lifestyle factors, and indeed a low HDL-C is a marker of poor overall health, rather a cardiovascular risk factor. We hypothesise that this is the case, and may explain why interventions to increase HDL-C have not translated into improved outcomes.
Our study must be interpreted in the context of several limitations that merit discussion. First, we did not have information on HDL-C levels for the full CANHEART population, but rather only a subset of whom a lipid profile was ordered. Nevertheless, this was a large population of over 600000 individuals. Second, we did not account for possible lipid-modifying treatments in our models. This is not feasible, as prescription information is only available for individuals over the age of 65 years in Ontario. Third, outcomes were ascertained by administrative codes which required a hospital admission, which may result in under-reporting of event rates. However, this would be consistent across HDL-C categories and should not be expected to bias our results in any particular direction. Finally, given the observational nature of our study, we cannot fully discount the potential role of HDL-C in cardiovascular disease. Specifically, HDL-C values which we evaluated have different information from HDL-C function and the latter may have different relationships with non-fatal outcome that our study cannot comment on. As such, our results should be considered hypothesis generating. 


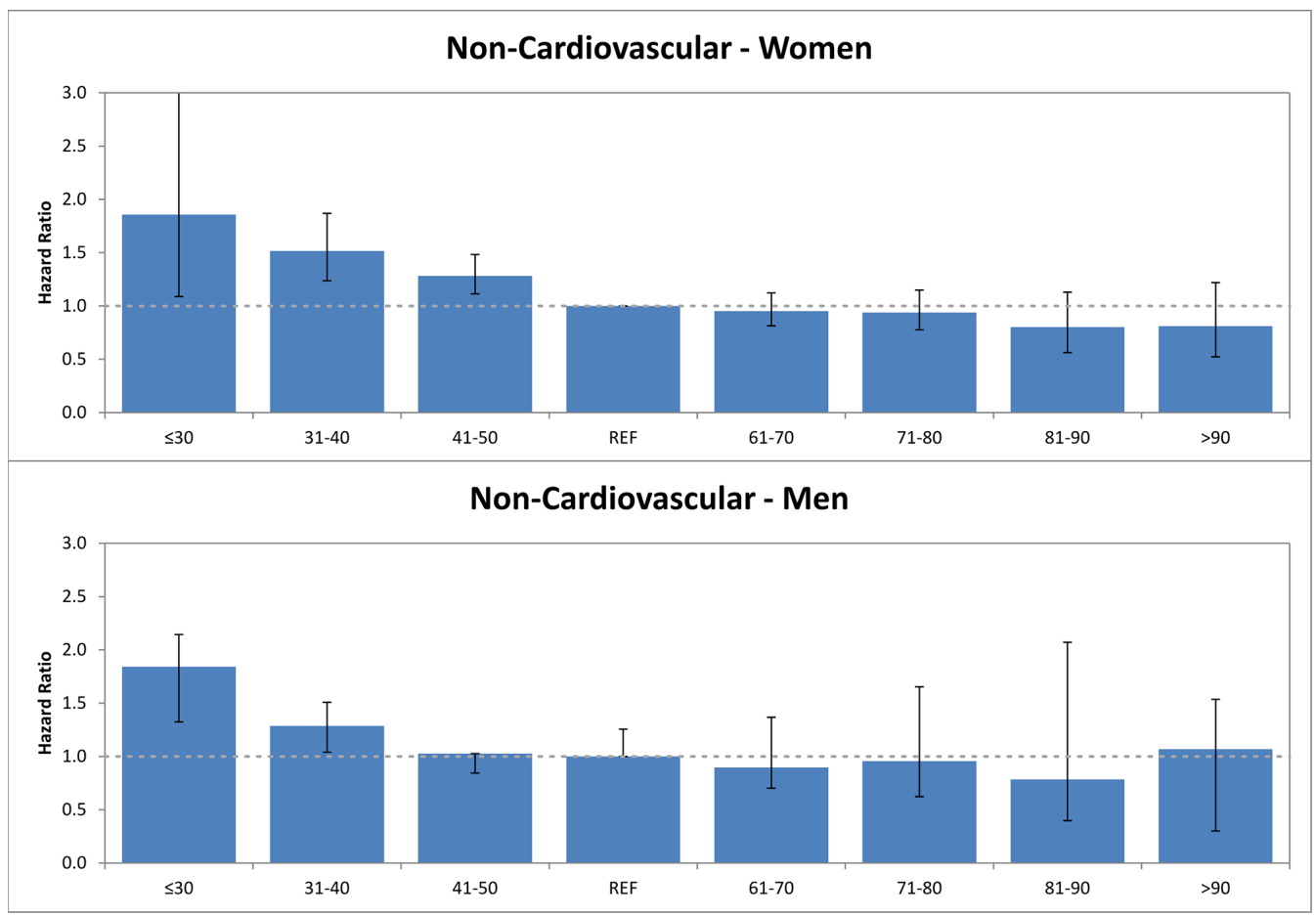

Figure 2 Non-fatal non-cardiovascular outcomes by high-density lipoprotein cholesterol (HDL-C) level. Adjusted causespecific HRs for each outcome are reported, compared with reference category $51-60 \mathrm{mg} / \mathrm{dL}$.

In conclusion, in a large primary prevention population of $>600000$ individuals, we found an inverse relationship between HDL-C levels and both non-fatal cardiovascular and non-cardiovascular outcomes. This reinforces the hypothesis that HDL-C is a heavily confounded factor that may be a marker of poor overall health, rather than an independent and modifiable risk factor.

Contributors HCW developed the concept, interpreted the results and drafted the manuscript. MK performed the analyses, interpreted the results and provided critical revision of the manuscript. DAA, PCA, CAJ and JVT interpreted the results and provided critical revision of the manuscript. DTK developed the concept, interpreted the results and provided critical revision of the manuscript. HCW had full access to all data in the study and takes responsibility for the integrity of the data and accuracy of the data analysis.

Funding The study was supported by the Institute for Clinical Evaluative Sciences (ICES), an operating grant from the Institute of Circulatory and Respiratory Health, Canadian Institutes of Health Research (ICRH-CIHR) Chronic Diseases Team (grant no. TCA 118349), a ClHR Foundation Grant (grant no. FDN-143313), a CIHR Operating Grant (grant no. MOP-111035) and a Canadian Vascular Network (CVN) seed grant. The CVN is supported by grants from the CIHR-ICRH, and the Institute of Aging in partnership with and supported by Hypertension Canada. ICES is funded by an annual grant from the Ontario Ministry of Health and Long-Term Care (MOHLTC). JVT is supported by a Tier 1 Canada Research Chair in Health Services Research and by an Eaton Scholar Award. HCW is supported by a Distinguished Clinical Scientist Award from the Heart and Stroke Foundation of Canada. DTK is supported by a Mid-Career Personnel Award from the Heart and Stroke Foundation, Ontario Provincial Office. PCA is supported by a Career Investigator Award from the Heart and Stroke Foundation, Ontario Provincial Office.

Disclaimer The opinions, results and conclusions reported in this paper are those of the authors and are independent of the funding sources. No endorsement by ICES or the Ontario MOHLTC is intended or should be inferred. Parts of this material are based on data and information compiled and provided by the Canadian Institute for Health Information. However, the analyses, conclusions, opinions and statements expressed herein are those of the authors, and not necessarily those of the Canadian Institute for Health Information.

Competing interests None declared.
Ethics approval The retrospective cohort study was approved by the Institutional Research Ethics Board at Sunnybrook Health Sciences Centre, Toronto, Ontario.

Provenance and peer review Not commissioned; externally peer reviewed.

Data sharing statement There are no additional unpublished data from this study.

Open Access This is an Open Access article distributed in accordance with the Creative Commons Attribution Non Commercial (CC BY-NC 4.0) license, which permits others to distribute, remix, adapt, build upon this work non-commercially, and license their derivative works on different terms, provided the original work is properly cited and the use is non-commercial. See: http://creativecommons.org/ licenses/by-nc/4.0/

(C) Article author(s) (or their employer(s) unless otherwise stated in the text of the article) 2017. All rights reserved. No commercial use is permitted unless otherwise expressly granted.

\section{REFERENCES}

1. Barter P, Gotto AM, LaRosa JC, et al. HDL cholesterol, very low levels of LDL cholesterol, and cardiovascular events. N Engl J Med 2007;357:1301-10.

2. Chapman MJ, Ginsberg HN, Amarenco P, et al. Triglyceride-rich lipoproteins and high-density lipoprotein cholesterol in patients at high risk of cardiovascular disease: evidence and guidance for management. Eur Heart J 2011;32:1345-61.

3. Di Angelantonio E, Sarwar N, Perry P, et al. Major lipids, apolipoproteins, and risk of vascular disease. JAMA 2009;302:1993-2000.

4. Halliday JS, Chapman RW. No more pilots, a phase III trial of fibrates in primary biliary cirrhosis is long overdue!. $J$ Gastroenterol Hepatol 2011;26:1345-6.

5. Kannel WB, Dawber TR, Friedman GD, et al. Risk factors in coronary heart disease. An evaluation of several serum lipids as predictors of coronary heart disease; the Framingham study. Ann Intern Med 1964;61:888-99.

6. Kontush A, Chapman MJ. Functionally defective high-density lipoprotein: a new therapeutic target at the crossroads of dyslipidemia, inflammation, and atherosclerosis. Pharmacol Rev 2006;58:342-74

7. Maron DJ. The epidemiology of low levels of high-density lipoprotein cholesterol in patients with and without coronary artery disease. Am J Cardiol 2000;86:11-14. 
8. Sharrett AR, Ballantyne CM, Coady SA, et al. Coronary heart disease prediction from lipoprotein cholesterol levels, triglycerides, lipoprotein(a), apolipoproteins A-I and B, and HDL density subfractions: The Atherosclerosis Risk in Communities (ARIC) Study. Circulation 2001;104:1108-13.

9. Gordon T, Castelli WP, Hjortland MC, et al. High density lipoprotein as a protective factor against coronary heart disease. The Framingham Study. Am J Med 1977;62:707-14.

10. Lewington S, Whitlock G, Clarke R, et al. Blood cholesterol and vascular mortality by age, sex, and blood pressure: a meta-analysis of individual data from 61 prospective studies with 55,000 vascular deaths. Lancet 2007;370:1829-39.

11. Rubenfire M, Brook RD. HDL cholesterol and cardiovascular outcomes: what is the evidence? Curr Cardiol Rep 2013;15:349.

12. Glomset JA, Janssen ET, Kennedy R, et al. Role of plasma lecithin:cholesterol acyltransferase in the metabolism of high density lipoproteins. J Lipid Res 1966;7:638-48.

13. Rader DJ, Hovingh GK. HDL and cardiovascular disease. Lancet 2014:384:618-25.

14. Katz PM, Leiter LA. Drugs targeting high-density lipoprotein cholesterol for coronary artery disease management. Can J Cardiol 2012;28:667-77.

15. Holmes MV, Asselbergs FW, Palmer TM, et al. Mendelian randomization of blood lipids for coronary heart disease. Eur Heart $J$ 2015;36:539-50.

16. Jørgensen AB, Frikke-Schmidt R, Nordestgaard BG, et al. Loss-offunction mutations in APOC3 and risk of ischemic vascular disease. N Engl J Med 2014;371:32-41.

17. Voight BF, Peloso GM, Orho-Melander M, et al. Plasma HDL cholesterol and risk of myocardial infarction: a mendelian randomisation study. Lancet 2012;380:572-80.

18. Barter PJ, Caulfield M, Eriksson M, et al. Effects of torcetrapib in patients at high risk for coronary events. N Engl J Med 2007;357:2109-22.

19. Cannon CP, Shah S, Dansky HM, et al. Safety of anacetrapib in patients with or at high risk for coronary heart disease. N Engl J Med 2010;363:2406-15.

20. Keene D, Price C, Shun-Shin MJ, et al. Effect on cardiovascular risk of high density lipoprotein targeted drug treatments niacin, fibrates, and CETP inhibitors: meta-analysis of randomised controlled trials including 117,411 patients. BMJ 2014;349:94379.

21. Schwartz GG, Olsson AG, Abt M, et al. Effects of dalcetrapib in patients with a recent acute coronary syndrome. N Engl J Med 2012;367:2089-99.

22. Ko DT, Alter DA, Guo H, et al. High-density lipoprotein cholesterol and cause-specific mortality in individuals without previous cardiovascular conditions: The CANHEART Study. J Am Coll Cardiol 2016;68:2073-83.

23. Chirovsky DR, Fedirko V, Cui Y, et al. Prospective studies on the relationship between high-density lipoprotein cholesterol and cardiovascular risk: a systematic review. Eur J Cardiovasc Prev Rehabil 2009;16:404-23.

24. Ahn J, Lim U, Weinstein SJ, et al. Prediagnostic total and highdensity lipoprotein cholesterol and risk of cancer. Cancer Epidemiol Biomarkers Prev 2009;18:2814-21.

25. Bowers K, Albanes D, Limburg P, et al. A prospective study of anthropometric and clinical measurements associated with insulin resistance syndrome and colorectal cancer in male smokers. Am $J$ Epidemiol 2006;164:652-64.

26. Furberg AS, Veierød MB, Wilsgaard T, et al. Serum high-density lipoprotein cholesterol, metabolic profile, and breast cancer risk. J Natl Cancer Inst 2004:96:1152-60.
27. Jacobs EJ, Stevens VL, Newton CC, et al. Plasma total, LDL, and $\mathrm{HDL}$ cholesterol and risk of aggressive prostate cancer in the Cancer Prevention Study II Nutrition Cohort. Cancer Causes Control 2012;23:1289-96.

28. Jafri H, Alsheikh-Ali AA, Karas RH. Baseline and on-treatment highdensity lipoprotein cholesterol and the risk of cancer in randomized controlled trials of lipid-altering therapy. J Am Coll Cardiol 2010;55:2846-54.

29. Touvier M, Fassier $\mathrm{P}$, His $\mathrm{M}$, et al. Cholesterol and breast cancer risk: a systematic review and meta-analysis of prospective studies. $\mathrm{Br} \mathrm{J}$ Nutr 2015;114:347-57.

30. van Duijnhoven FJ, Bueno-De-Mesquita HB, Calligaro M, et al. Blood lipid and lipoprotein concentrations and colorectal cancer risk in the European Prospective Investigation into Cancer and Nutrition. Gut 2011:60:1094-102.

31. Van Hemelrijck M, Walldius G, Jungner I, et al. Low levels of apolipoprotein $\mathrm{A}-\mathrm{I}$ and $\mathrm{HDL}$ are associated with risk of prostate cancer in the Swedish AMORIS study. Cancer Causes Control 2011;22:1011-9.

32. Yang MH, Rampal S, Sung J, et al. The association of serum lipids with colorectal adenomas. Am J Gastroenterol 2013;108:833-41.

33. Chien JY, Jerng JS, Yu CJ, et al. Low serum level of high-density lipoprotein cholesterol is a poor prognostic factor for severe sepsis. Crit Care Med 2005;33:1688-93.

34. Chien YF, Chen CY, Hsu CL, et al. Decreased serum level of lipoprotein cholesterol is a poor prognostic factor for patients with severe community-acquired pneumonia that required intensive care unit admission. J Crit Care 2015;30:506-10.

35. Deniz O, Tozkoparan E, Yaman H, et al. Serum HDL-C levels, $\log (\mathrm{TG} / \mathrm{HDL}-\mathrm{C})$ values and serum total cholesterol/HDL-C ratios significantly correlate with radiological extent of disease in patients with community-acquired pneumonia. Clin Biochem 2006;39:287-92.

36. Grion CM, Cardoso LT, Perazolo TF, et al. Lipoproteins and CETP levels as risk factors for severe sepsis in hospitalized patients. Eur $J$ Clin Invest 2010;40:330-8.

37. Laurila A, Bloigu A, Näyhä S, et al. Chlamydia pneumoniae antibodies and serum lipids in Finnish men: cross sectional study. BMJ 1997;314:1456.

38. Lekkou A, Mouzaki A, Siagris D, et al. Serum lipid profile, cytokine production, and clinical outcome in patients with severe sepsis. J Crit Care 2014;29:723-7.

39. Tu JV, Chu A, Donovan LR, et al. The Cardiovascular Health in Ambulatory Care Research Team (CANHEART): using big data to measure and improve cardiovascular health and healthcare services. Circ Cardiovasc Qual Outcomes 2015;8:204-12.

40. McPherson R, Frohlich J, Fodor G, et al. Canadian Cardiovascular Society position statement- recommendations for the diagnosis and treatment of dyslipidemia and prevention of cardiovascular disease. Can J Cardiol 2006;22:913-27.

41. Austin PC, Lee DS, Fine JP. Introduction to the Analysis of Survival Data in the Presence of Competing Risks. Circulation 2016;133:601-9.

42. Lau B, Cole SR, Gange SJ. Competing risk regression models for epidemiologic data. Am J Epidemiol 2009;170:244-56.

43. Austin PC, van Walraven C, Wodchis WP, et al. Using the Johns Hopkins Aggregated Diagnosis Groups (ADGs) to predict mortality in a general adult population cohort in Ontario, Canada. Med Care 2011;49:932-9

44. Arsenault BJ, Boekholdt SM, Kastelein JJ. Lipid parameters for measuring risk of cardiovascular disease. Nat Rev Cardiol 2011;8:197-206.

45. Kastelein JJP. Dyslipidaemia in perspective. Lancet 2014;384:566-8. 